Rev. Biol. Trop., 47(1-2): 69-81, 1999

www.ucr.ac.cr www.ots.ac.cr www.ots.duke.edu

\title{
Morfogénesis de la fase sexual de seis especies mexicanas de helechos del género Dryopteris (Dryopteridaceae)
}

\author{
Blanca Pérez-García, Aniceto Mendoza, Irma Reyes Jaramillo y Ramón Riba \\ Depto. de Biología, Área de Botánica, C. B. S., Universidad Autónoma Metropolitana-Iztapalapa, Apartado Postal 55- \\ 535, 09340 México, D. F., Fax (52 5) 72446 88, bpg@xanum.uam.mx
}

Recibido 1-VI-1998. Corregido 9-X-1998. Aceptado 30-X-1998.

\begin{abstract}
The development of the sexual phase of six Mexican species of the fern Dryopteris is described and compared. The spores of all six species are monolete, ellipsoid, the perine is folded, brown to dark brown, with a tubercled outline. The germination pattern of the species is Vittaria-type and the development pattern of the prothallia is Aspidium-type. The gametangia are the common sort for the leptosporangiate advanced ferns, the necks of the archegonia have four rows of cells, with 4-5 cells each and appear 53-218 days after the sowing of the spores. The antheridia appear 46-234 days after the sowing, have three cells surrounding the androgenic cell. The first leaves of the sporophytes appear 60-262 after the sowing and, apparently in D. munchii and D. wallichiana the sporophytes have an apogamic origin.
\end{abstract}

Key words: Apogamy, Dryopteris, Dryopteridaceae, gametophytes, México, morphogenesis, prothallus, pteridophyta.

La familia Dryopteridaceae Herter está conformada por 16 géneros con más de 400 especies. En México se encuentra representada por los géneros: Arachniodes, Didymochlaena, Dryopteris, Olfersia, Phanerophlebia, Polybotrya, Polystichum y Stigmatopteris. Son plantas terrestres, epipétricas o epífitas, con tallos o rizomas erectos con escamas, tienen los ejes foliares sulcados adaxialmente, con los surcos decurrentes, con tres o más haces vasculares en el pecíolo, esporas monoletes aclorofílicas y número cromosómico $n=41$ (Moran 1995).

Algunos géneros de la familia Dryopteridaceae que crecen en México han sido estudiados desde el punto de vista taxonómico por Moran (1986, 1987a, 1987b, 1991), Yatskievych $(1990,1992)$ y actualmente Riba y Pérez-García (1998) hacen un estudio florístico de la misma. Sin embargo, no existen estudios de la fase sexual del ciclo de vida para las especies mexicanas del género Dryopteris, no obstante que de acuerdo con la literatura, se ha constatado que las características morfológicas de los gametofitos son útiles para delimitar familias, como en el caso de Grammitidaceae, Schizaeaceae y a nivel genérico: Oleandra, Nephrolepis, Davallia y Humata (Atkinson 1973).

Como resultado de la revisión bibliográfica sólo se han encontrado estudios de la fase sexual de especies que crecen en el Viejo Mundo de géneros tales como Arachniodes, Cyrtomium, Polystichum (Chandra y Nayar 1970), Didymochlaena (Stokey y Atkinson 1954c) y Dryopteris (Momose 1937, Duncan 1943, Loyal 1959, Kanamori 1967, Cousens y Horner 1970, Cousens 1975, Kaur 1977) y el trabajo sobre el género Didymochlaena en México de Mendoza et al. (1999). 
En el presente trabajo se hace una descripción y comparación de la morfogénesis de seis especies de Dryopteris recolectadas en México: Dryopteris cinnamomea (Cav.) C. Chr., D. karwinskyana (Mett.) Kuntze, D. maxonii Underw. et C. Chr. ex C. Chr., D. munchii A.R. Sm. (especie endémica del estado de Chiapas), D. rossii C. Chr. y D. wallichiana (Spreng.) Hyl.

\section{MATERIALES Y MÉTODOS}

Las especies de Dryopteris estudiadas se recolectaron en distintas localidades del país como se indica en el Cuadro 1. Los ejemplares de respaldo se depositaron en el Herbario UAMIZ.

\section{CUADRO 1}

Especies estudiadas de Dryopteris.

\begin{tabular}{|c|c|c|c|c|}
\hline Especies & No. colecta & Localidad & Habitats/Altitud & Fecha \\
\hline \multirow[t]{2}{*}{ D. cinnamomea } & AMR-68 & $\begin{array}{l}\text { Autopista Cuernavaca-México, km } 72.5 \text { salida } \\
\text { a la carretera Cuautla-Oaxtepec, Morelos. }\end{array}$ & $\mathrm{BPE} / 2225 \mathrm{~m}$ & 13-IX-1994 \\
\hline & AMR-80 & $\begin{array}{l}\text { Cerro de Iztapalapa rumbo a Tlacatenango, } \\
\text { ca. de la estación del tren el Parque, Morelos. }\end{array}$ & $\mathrm{BPE} / 2200 \mathrm{~m}$ & 14-IX-1994 \\
\hline \multirow[t]{2}{*}{ D. karwinskyana } & IRJ-63 & $\begin{array}{l}\text { Rincón de Ugarte, Tejupilco de Hidalgo, } \\
\text { Edo. México. }\end{array}$ & $\mathrm{BE} / 1340 \mathrm{~m}$ & 27-VIII-1994 \\
\hline & RR-1908 & $\begin{array}{l}\text { Sierra del Tepozteco, camino a las Pirámides, } \\
\text { Tepoztlán, Morelos. }\end{array}$ & $\mathrm{BE} / 1800-2000 \mathrm{~m}$ & 28-XI-1994 \\
\hline \multirow[t]{2}{*}{ D. maxonii } & IRJ-5b & Tejupilco de Hidalgo, Edo. de México. & $\mathrm{BE} / 1340 \mathrm{~m}$ & 02-XI-1993 \\
\hline & IRJ-64 & $\begin{array}{l}\text { Rincón de Ugarte, Tejupilco de Hidalgo, Edo. } \\
\text { México. }\end{array}$ & $\mathrm{BE} / 1340 \mathrm{~m}$ & 01-XI-1994 \\
\hline \multirow[t]{2}{*}{ D. munchii } & AMR-182 & $\begin{array}{l}\text { Paraje Banabil, } 5 \text { km sobre la desviación a } \\
\text { Matzab, a partir de la carretera San Cristóbal } \\
\text { de las Casas-Tenejapa, Chiapas. }\end{array}$ & $\mathrm{BPE} / 1400 \mathrm{~m}$ & 20-XI-1996 \\
\hline & AMR-244 & $\begin{array}{l}\text { Paraje Banabil, } 5 \text { km sobre la desviación a } \\
\text { Matzab, a partir de la carretera San Cristóbal } \\
\text { de las Casas-Tenejapa, Chiapas. }\end{array}$ & $\mathrm{BPE} / 1400 \mathrm{~m}$ & 05-XI-1997 \\
\hline \multirow[t]{2}{*}{ D. rossii } & AMR-75 & $\begin{array}{l}\text { Autopista Cuernavaca-México, km 72, salida a } \\
\text { la carretera Cuautla-Oaxtepec, Cuernavaca, } \\
\text { Morelos. }\end{array}$ & $\mathrm{BPE} / 2200 \mathrm{~m}$ & 14-IX-1994 \\
\hline & IRJ-37 & Tejupilco de Hidalgo, Edo. México. & $\mathrm{BE} / 1340 \mathrm{~m}$ & 28-VIII-1994 \\
\hline \multirow[t]{2}{*}{ D. wallichiana } & BPG-1014 & $\begin{array}{l}\text { Sierra del Tepozteco, camino a la Pirámide, } \\
\text { Tepoztlán, Morelos. }\end{array}$ & $\mathrm{BP} / 2740 \mathrm{~m}$ & 28-XI-1994 \\
\hline & IRJ-17 & $\begin{array}{l}10 \mathrm{~km} \text { al NE de Tetela de Ocampo, rumbo a } \\
\text { Huahuaxtla, ca. } 300 \mathrm{~m} \text { antes del } \\
\text { Puerto, Puebla. }\end{array}$ & $\mathrm{BPA} / 2000 \mathrm{~m}$ & 06-XI-1993 \\
\hline
\end{tabular}

Recolectores: AMR= Aniceto Mendoza Ruíz, BPG= Blanca Pérez-García, IRJ= Irma Reyes Jaramillo, RR= Ramón Riba. Localidades y hábitats: BE= Bosque de Encino, BP= Bosque de Pino, BPA= Bosque de Pino-Abies, BPE= Bosque de Pino-Encino. 
Las esporas se obtuvieron de hojas fértiles de diferentes individuos y se guardaron en sobres de papel, dejandolas secar a temperatura ambiente para propiciar la apertura de los esporangios y la liberación de las esporas. La separación de los esporangios y fragmentos de hojas, se llevó a cabo con un tamiz con malla de $0.074 \mathrm{~mm}$ de diámetro. Las esporas de cada especie se sembraron sin previa esterilización, en cuatro cajas de Petri de $5 \mathrm{~cm}$ de diámetro con tres repeticiones, con una densidad promedio de 240 esporas por $\mathrm{cm}^{2}$ esparcidas sobre la superficie del agar con medio de cultivo de Thompson (Klekowski 1969), con pinceles de pocas cerdas. Seis cajas (una por especie) se mantuvieron en condiciones de obscuridad para determinar el fotoblastismo.

Las cajas de Petri sembradas se guardaron en bolsas de polietileno transparente, para evitar su contaminación y deshidratación.

Los cultivos se mantuvieron en condiciones de laboratorio, con un fotoperíodo de $12 \mathrm{hr}$ luz-oscuridad, empleando luz artificial (75 watts, luz de día), bajo una temperatura de 18$251^{\circ} \mathrm{C}$. Se hicieron observaciones de los gametofitos durante todo su desarrollo.

Las fotomicrografías se obtuvieron de gametofitos y esporofitos vivos.

\section{RESULTADOS}

Esporas: son monoletes, elipsoidales, con perina de color pardo a pardo obscuro, su superficie es rugosa, de contornos tuberculados y la perina en forma de pliegues (Tryon y Lugardon 1991). Las esporas de menor tamaño fueron las de $D$. rossii con 28 (40)44 $\mu \mathrm{m}$ por 24(29)32 $\mu \mathrm{m}$ y las más grandes fueron de $D$. karwinskyana con 52(59)68 $\mu \mathrm{m}$ por $40(42) 48$ $\mu \mathrm{m}$ (Figs. 1-3).

Germinación: la germinación se inicia en un período de 7-15 días después de la siembra. Primero se forma la célula rizoidal hialina, seguida de la célula protálica rica en cloroplastos; en esta fase se conserva la cubierta de la espora (Figs. 4-6). Los cultivos que se mantu- vieron en la obscuridad no germinaron después de 100 días, por lo tanto las esporas de las seis especies en estudio son fotoblásticas positivas.

Fase filamentosa: en general inicia su desarrollo entre los 9-27 días, en promedio se compone de 2 a 9 células, formándose el filamento más largo en $D$. wallichiana. Las células de los filamentos germinativos tienen forma de barril a excepción de $D$. wallichiana, especie en la que las células basales son más alargadas que las apicales. Tienen abundantes cloroplastos y se observaron glóbulos de grasa. Se desarrolla un rizoide hialino tan largo como el filamento protálico (Figs. 7-9).

Fase laminar: los gametofitos de las seis especies forman la lámina protálica en un período que varía de 22-48 días.

El desarrollo protálico Aspidium (Nayar y Kaur 1969, 1971), consiste en la formación temprana de tricomas en el protalo joven, donde la célula terminal del filamento germinal produce un tricoma unicelular (Fig. 10).

La formación de la lámina se inicia por las células que están por detrás de la célula terminal, las que se dividen longitudinalmente. En un principio la lámina protálica es ligeramente asimétrica con una ala más desarrollada que la otra y continuamente se producen tricomas marginales (Fig. 11). El protalo sigue creciendo por la actividad de una célula meristemática obcónica inicial de la que se deriva un meristemo pluricelular formando una muesca central (Fig. 15). Finalmente en la mayoría de los protalos las alas se desarrollan simétricamente adquiriendo la forma espatulada o cordiforme, con un cojinete central incipiente, alas isodiamétricas (Figs. 12-15), tricomas simples (Figs. 16-18) y rizoides hialinos.

Fase adulta: en el intervalo comprendido entre los 50-110 días de sembradas las esporas, los protalos adultos son espatulados, cordiformes, cordiforme-espatulados y algunos de aspecto acintado. Como es característico del género Dryopteris presentan numerosos tricomas marginales y en menor número superficiales, 


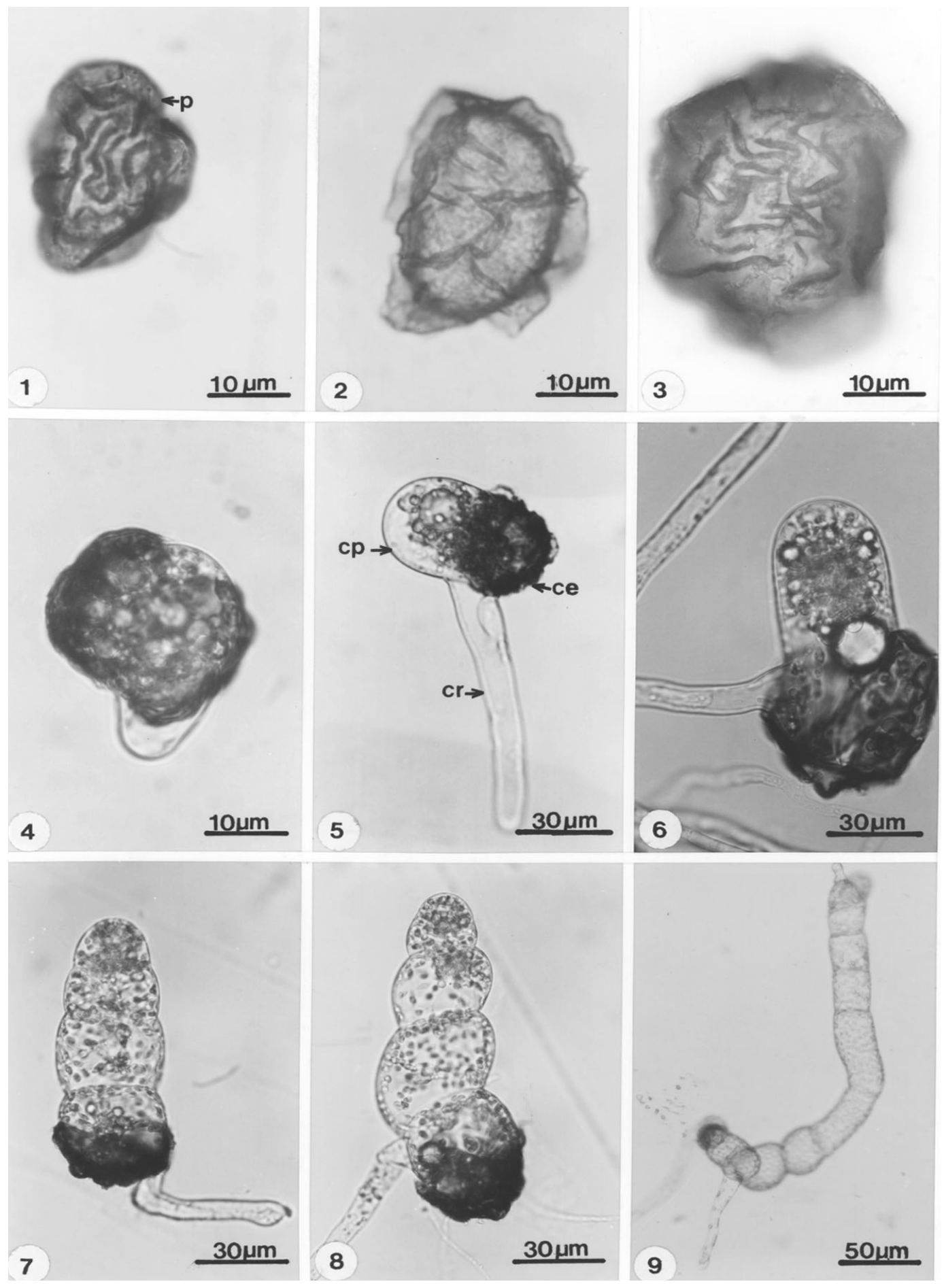

Figs. 1-9. Esporas y germinación de Dryopteris spp. 1. Espora, D. rossii. 2. D. munchii, 3. D. karwinskyana. 4-6. Inicio de la germinación. 4. D. cinnamomea (12 días). 5-6. D. karwinskyana (9 días). 7-9. Filamento germinativo. 7-8. D. maxonii (12 días). 9. $D$. wallichiana ( 9 días). ce= cubierta de la espora, $\mathrm{cp}=$ célula protálica, $\mathrm{cr}=$ célula rizoidal, $\mathrm{p}=$ perina. 

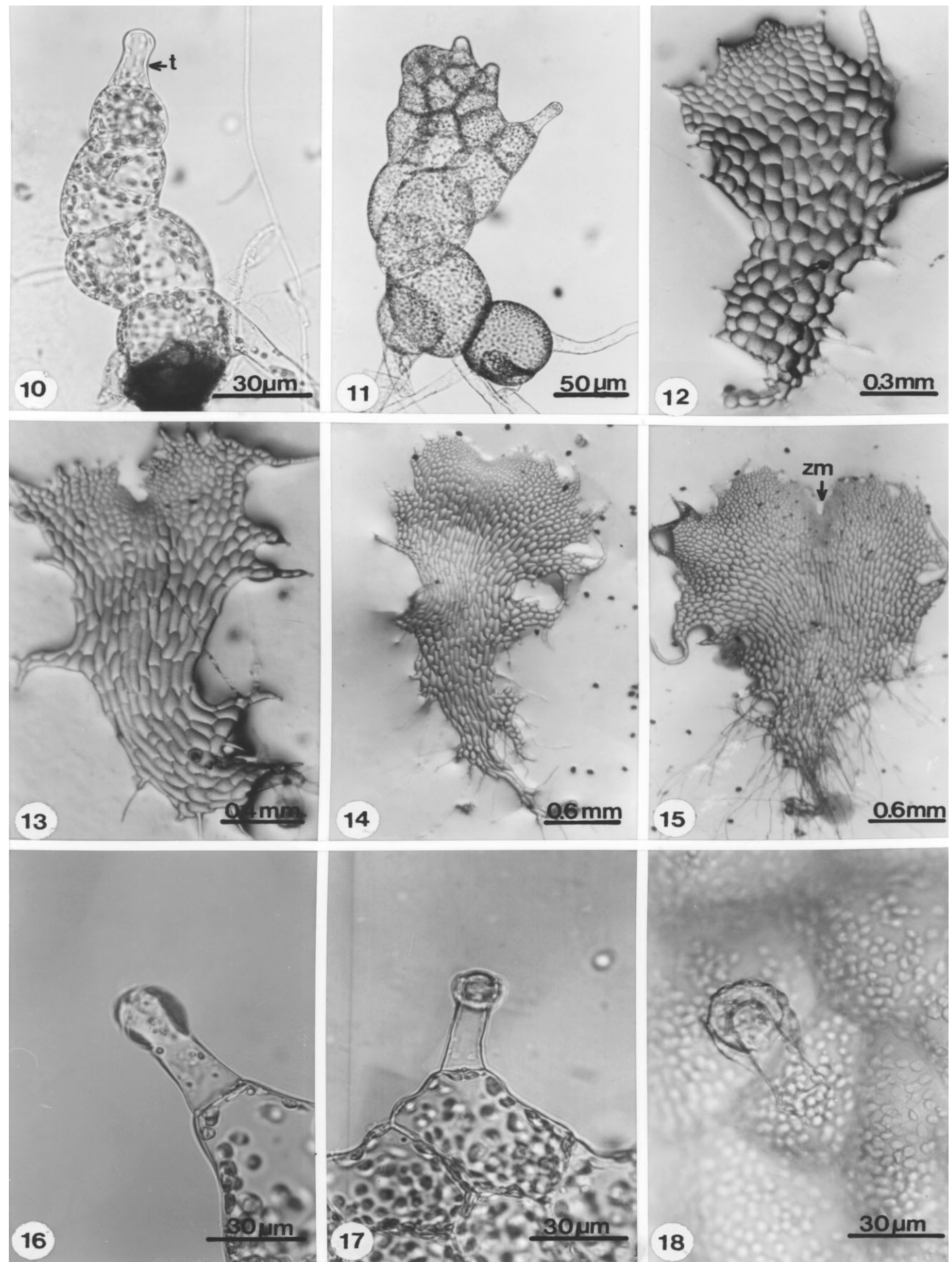

Figs. 10-18. Gametofitos bidimensionales y tricomas unicelulares capitados. 10. D. maxonii (12 días). 11. D. munchii (18 días). 12. D. wallichiana (51 días). 13. D. karwinskyana (28 días). 14-15. D. cinnamomea (40 días). 16. Tricoma marginal, D. wallichiana (217 días). 17. Tricoma marginal, D. karwinskyana (234 días). 18. Tricoma superficial, D. maxonii (136 días). $\mathrm{t}=$ tricoma, $\mathrm{zm}=$ zona meristemática. 
el margen de las alas de los gametofitos tiene un aspecto irregular que hemos denominado lacerado.

Dryopteris cinnamomea: los talos son cordiformes con un meristemo central pluricelular formando una muesca bien definida, con alas isodiamétricas amplias que muestran ondulaciones marginales laceradas, con tricomas unicelulares, capitados; presenta un cojinete bien definido en la parte media central, donde se forman los gametangios (Figs. 19-21). Los rizoides son hialinos alargados y abundantes en la región basal, forma gametofitos de tres tipos: bisexuales, masculinos y femeninos.

D. karwinskyana: los talos son cordiforme-espatulados, alargados y otros de aspecto acintado, tienen alas simétricas estrechas con márgenes lacerados, la muesca meristemática es central, en los primeros está bien definida y en los segundos no es clara, presenta tricomas unicelulares marginales y superficiales, el cojinete es inconspicuo y los gametangios se forman en la parte media central a lo largo de todo el gametofito, el cual puede ser bisexual, masculino o femenino; forma escasos rizoides cortos y hialinos (Figs. 22-24).

D. maxonii: es cordiforme o cordiformeespatulado, con abundantes tricomas marginales unicelulares sobre el margen lacerado, el cojinete está bien definido en la parte media central del gametofito, donde se forman los gametangios; se observaron protalos dioicos (Fig. 25).

D. munchii: el protalo es cordiforme, se caracteriza por tener la escotadura del meristemo pluricelular central profunda, separando las alas isodiamétricas que le dan la apariencia de "mariposa" con los margenes lacerados; presentan tricomas unicelulares marginal y superficialmente, el cojinete es inconspicuo (Fig. 26). Forma esporofitos apogámicos derivados de gametofitos inicialmente asexuados en los que después del desarrollo del esporofito se di- ferencian algunos anteridios; los gametofitos masculinos son de menor tamaño (Fig. 27), no se observaron protalos bisexuales.

D. rossii: el protalo es cordiforme, es la especie que tiene los márgenes de las alas menos lacerados, forma abundantes tricomas unicelulares en el margen y en menor número en la superficie, las alas son isodiamétricas divididas por una suave escotadura meristemática apical central. El cojinete no está bien definido y los gametangios se forman en la región media central del protalo, el cual puede ser bisexual, masculino o femenino (Fig. 28).

D. wallichiana: la forma de este protalo es quizá la más difícil de describir de las seis especies, en algunas ocasiones se asemeja a la cordiforme y en otras la muesca central es tan profunda que abarca casi la mitad de la longitud del gametofito, generando dos alas estrechas y alargadas como cintas. Presenta al igual que las especies anteriores tricomas marginales y superficiales unicelulares, el cojinete es inconspicuo. Forma esporofitos apogámicos, y al igual que $D$. munchii formó protalos masculinos únicamente. Los rizoides son largos, delgados y hialinos parecidos a las demás especies descritas (Fig. 29).

Gametangios: en los protalos bisexuales y femeninos (D. cinnamomea, D. karwinskyana, D. maxonii y D. rossii) los arquegonios se forman en el cojinete entre los 53-218 días, son del tipo avanzado (Atkinson y Stokey 1964), los cuellos están formados por cuatro hileras de células con 4 a 5 células cada una (Figs. 30, 31). La célula del canal central es binucleada y alargada distalmente. El diámetro del cuello de los arquegonios es más ancho en el ápice que en su base e inclinado ligeramente hacia la región basal del gametofito. En D. munchii y D. wallichiana no se formaron arquegonios.

Los anteridios de las seis especies se formaron entre los 46-234 días después de sembradas las esporas, en los protalos bisexuales se localizan en la región media basal del protalo próxima a los rizoides. En los gametofitos masculinos y en los apogámicos se forman sobre la superficie 

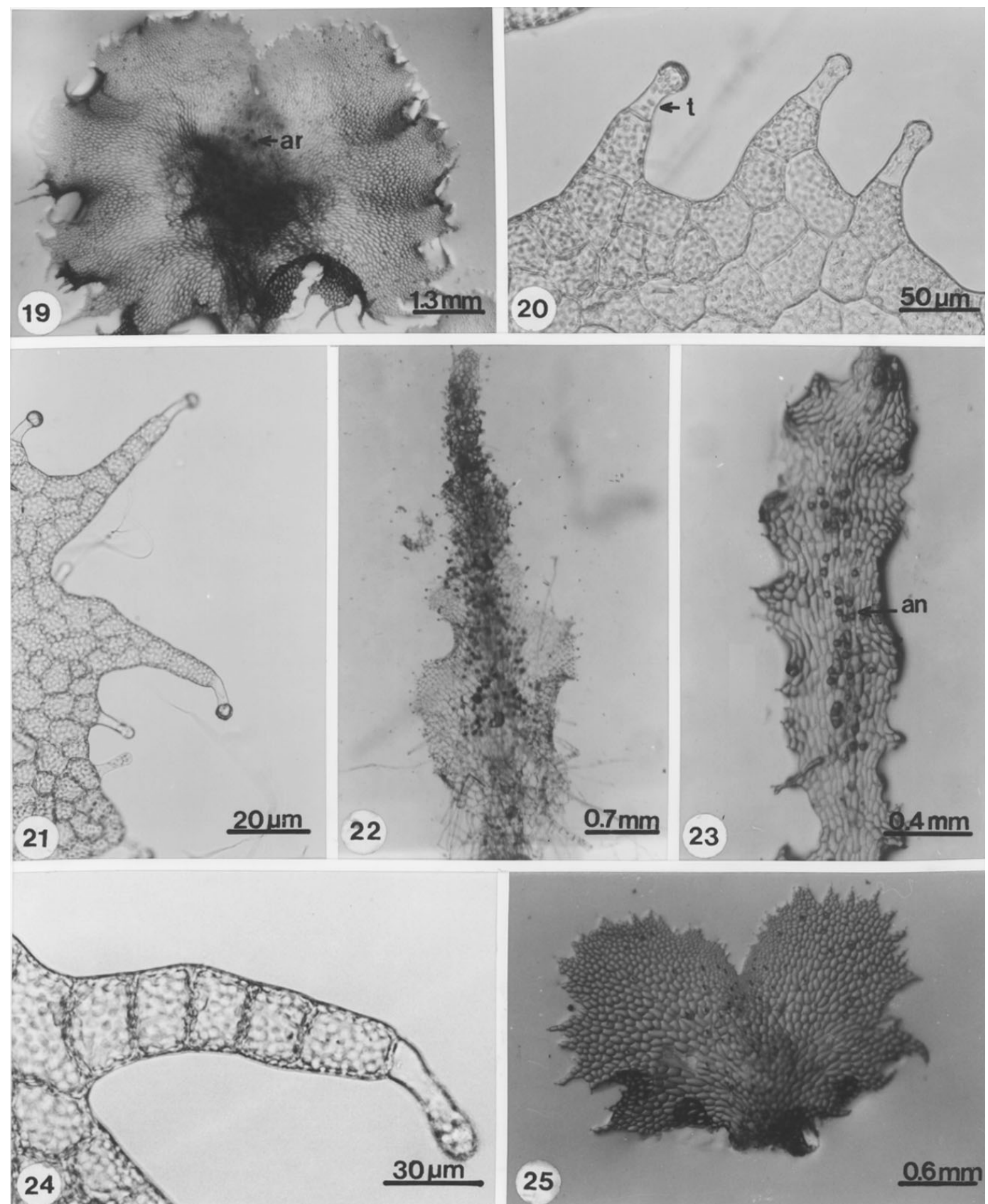

Figs. 19-25. Fase adulta. 19. Protalo adulto, D. cinnamomea (79 días). 20-21. Tricomas marginales, D. cinnamomea (40 y 56 días). 22-23. Protalos con gametangios, $D$. karwinskyana (190 y 65 días), 24. Tricoma marginal, D. karwinskyana (90 días). 25. Protalo cordiforme, $D$. maxonii ( 53 días). an= anteridio, ar= arquegonio, $\mathrm{t}=$ tricoma.

de las alas (Fig. 27) o, como en D. karwinskya$n a$, se distribuyen a todo lo largo de la región media central (Fig. 22). Están formados por una célula basal, una célula media anular que rodea a la célula central androgonial primaria y una célula opercular no dividida (Fig. 32).

En D. karwinskyana, D. rossii y D. wallichiana la célula basal del anteridio es compa- 

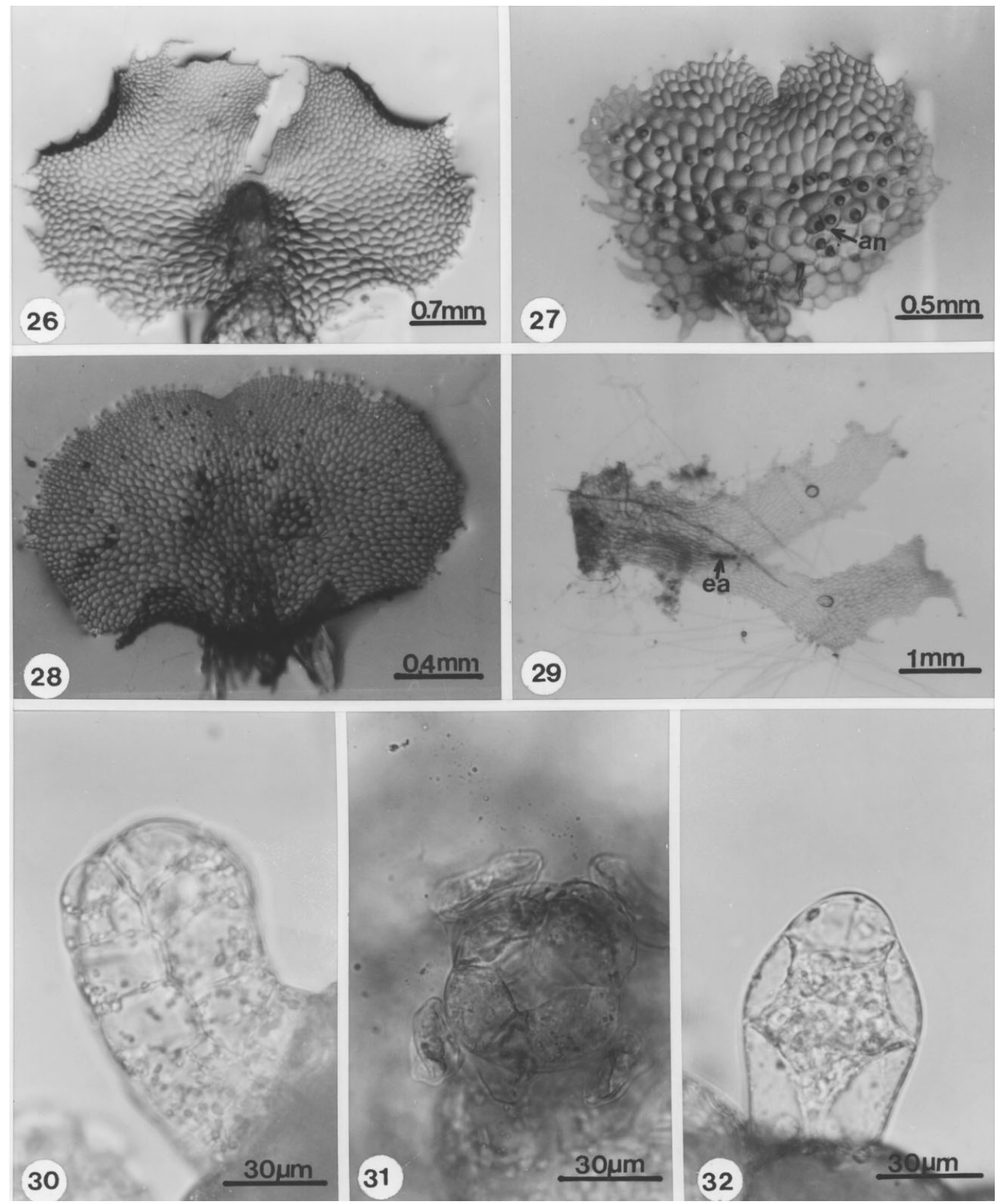

Figs. 26-32. Fase adulta y gametangios de Dryopteris spp. 26. Protalo, D. munchii (61 días). 27. Protalo masculino, D. munchii (61 días). 28. Protalo cordiforme, D. rossii (53 días). 29. D. wallichiana (84 días). 30. Cuello de arquegonio, D. maxonii (300 días). 31. Boca de arquegonio, D. cinnamomea (66 días). 32. Anteridio, D. wallichiana (217 días). ea= embrión apogámico, an= anteridio.

rativamente más estrecha en la base y más alta (Fig. 33) que las de D. cinnamomea, D. maxonii y D. munchii (Fig. 34).
En todas las especies la dehiscencia del anteridio es por el desprendimiento de la célula opercular (Fig. 35). 

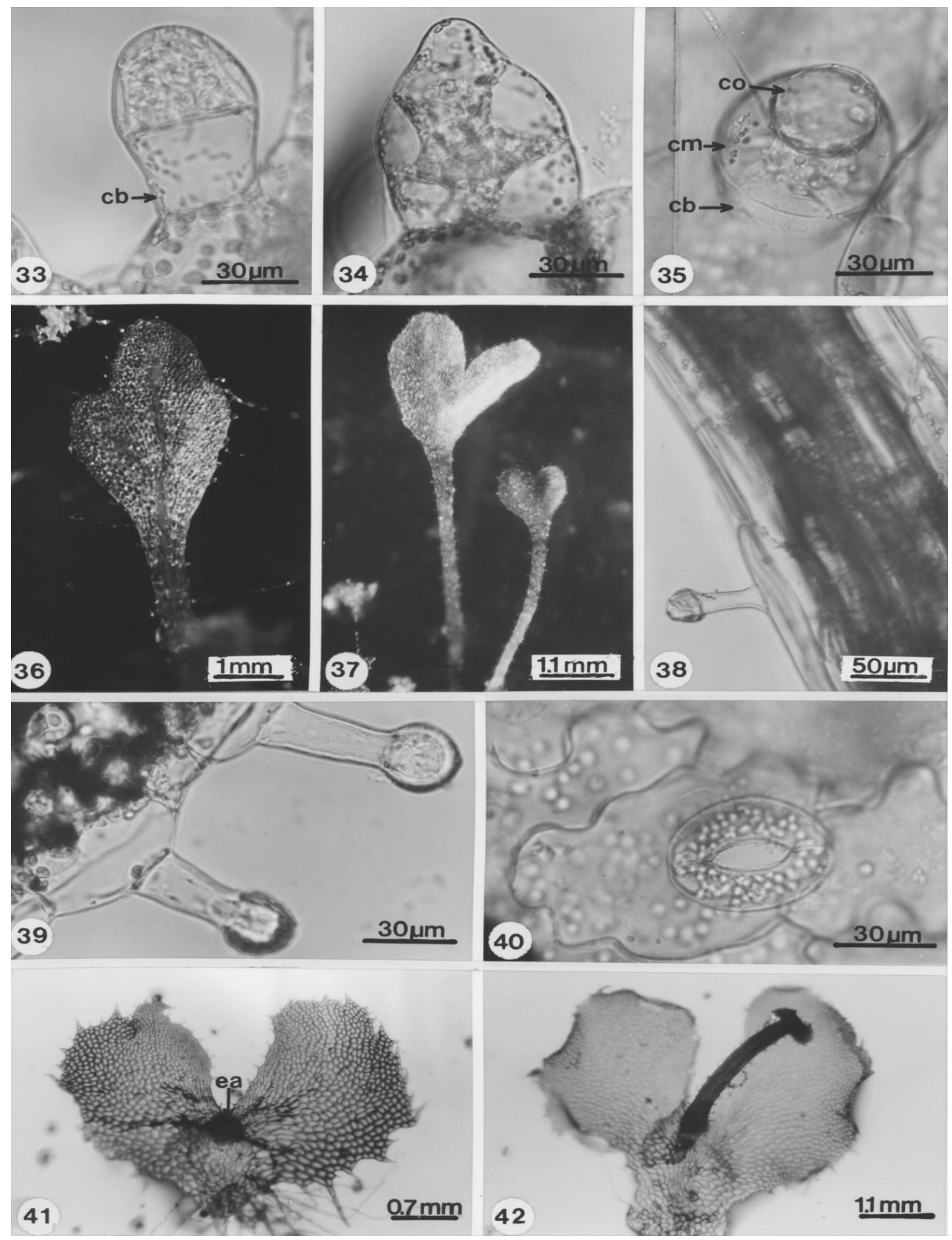

Figs. 33-42. Anteridios y esporofitos de Dryopteris. 33. Anteridio, D. rossii (267 días). 34. Anteridio, D. cinnamomea (141 días). 35. Anteridio, D. karwinskiana (234 días). 36. Esporofito, D. karwinskyana (190 días). 37-38. Hojas y pecíolo, D. rossii (281, 267 días). 39. Tricomas marginales de la lámina, D. karwinskyana (195 días). 40. Estoma, D. rossii (218 días). 41-42. Embrión y esporofito apogámico, D. munchii (74 días). $\mathrm{cb}=$ célula basal, $\mathrm{cm}=$ célula media, co= célula opercular, ea= embrión apogámico. 
Esporofitos: se formaron entre los 60-262 días después de sembradas las esporas, como producto de la fecundación $(D$. cinnamomea, $D$. karwinskyana, D. maxonii y $D$. rossii) o son de origen apogámico (D. munchii y D. wallichiana).

Las primeras hojas de los esporofitos de las seis especies, están formadas por un pecíolo y una lámina entera bi-trilobulada, con venación dicotómica abierta. El pecíolo, así como el margen y ambas superficies de la lámina tienen tricomas unicelulares y bicelulares, secretores, y estomas del tipo anomocítico, las células de la epidermis tienen paredes laterales onduladas (Figs. 36-40).

Los esporofitos apogámicos de D. munchii y $D$. wallichiana se formaron alrededor de 60 días después de sembradas las esporas, como resultado de divisiones de las células del cojinete próximas a la escotadura de la lámina protálica.

\section{DISCUSIÓN}

El presente estudio de la morfogénesis de los gametofitos de seis especies de Dryopteris nos ha permitido realizar comparaciones entre ellas, ya que si bien tienen características en común, también tienen diferencias particulares (véase cuadro 2).

El tamaño de las esporas varía en las seis especies, siendo las $D$. rossii las más pequeñas y las más grandes de $D$. karwinskyana. Las esporas de $D$. wallichiana y $D$. cinnamomea son casi de las mismas dimensiones y algo semejante se encontró entre $D$. maxonii y $D$. munchii (Cuadro 2).

El tipo de germinación y de desarrollo protálico es el mismo para las seis especies.

La formación de abundantes tricomas unicelulares principalmente en los márgenes lacerados, es una característica que comparten todas las especies estudiadas. Sin embargo, Atkinson y Stokey (1964) seguramente clasificarían a los tricomas observados en las especies de Dryopteris dentro de tres categorías: unicelulares, pluricelulares uniseriados (dos a más células) y pluricelulares ramificados. Nosotros no estamos de acuerdo con esta clasificación, ya que los pelos multicelulares que Atkinson y Stokey observaron, son crecimientos celulares irregulares de la lámina protálica, formando márgenes irregulares lacerados, cuyas células terminales siempre forman un pelo unicelular capitado. Esta condición se observó con mayor frecuencia en los protalos de D. karwinskyana, D. cinnamomea y D. munchii .

Las especies con gametofitos que desarrollan amplias alas son: D. cinnamomea, D. rossii y $D$. munchii, en ésta última al igual que en D. wallichiana es notable el hecho de que el exagerado crecimiento de las alas deja muy atrás a la muesca meristemática, reduciendo el área del cojinete.

Con relación a la expresión sexual de los gametofitos, se observó un comportamiento similar a lo observado por Cousens y Horner (1970) y Cousens (1975) para diferentes especies de Dryopteris, pues sugieren que los gametofitos de este género no son regularmente bisexuales, condición que nosotros también observamos, al encontrar en nuestros cultivos el desarrollo de protalos masculinos, femeninos y bisexuales.

Lo anterior favorece la recombinación genética ya que se puede llevar a cabo fecundación intragametofítica e intergametofítica y, como menciona Cousens (1975), el patrón de expresión sexual que se presenta en Dryopteris le puede conferir una mayor posibilidad de adaptación ante los procesos de selección natural.

Los esporofitos de $D$. munchii y $D$. wallichiana son de origen apogámico, ya que en los protalos no se desarrolla un cojinete ni arquegonios, por lo que el desarrollo del embrión es a partir de las células que se localizan inmediatamente por abajo de la escotadura meristemática, como lo demuestran los trabajos de Duncan (1943), Manton y Walker (1954), Loyal (1959), Kanamori (1967), Cousens y Horner (1970) y Cousens (1975) los cuales se han referido también al fenómeno de la apogamia, observado en otras especies de Dryopteris. En los cultivos de estas especies sólo se observaron protalos masculinos de menor tamaño, con 


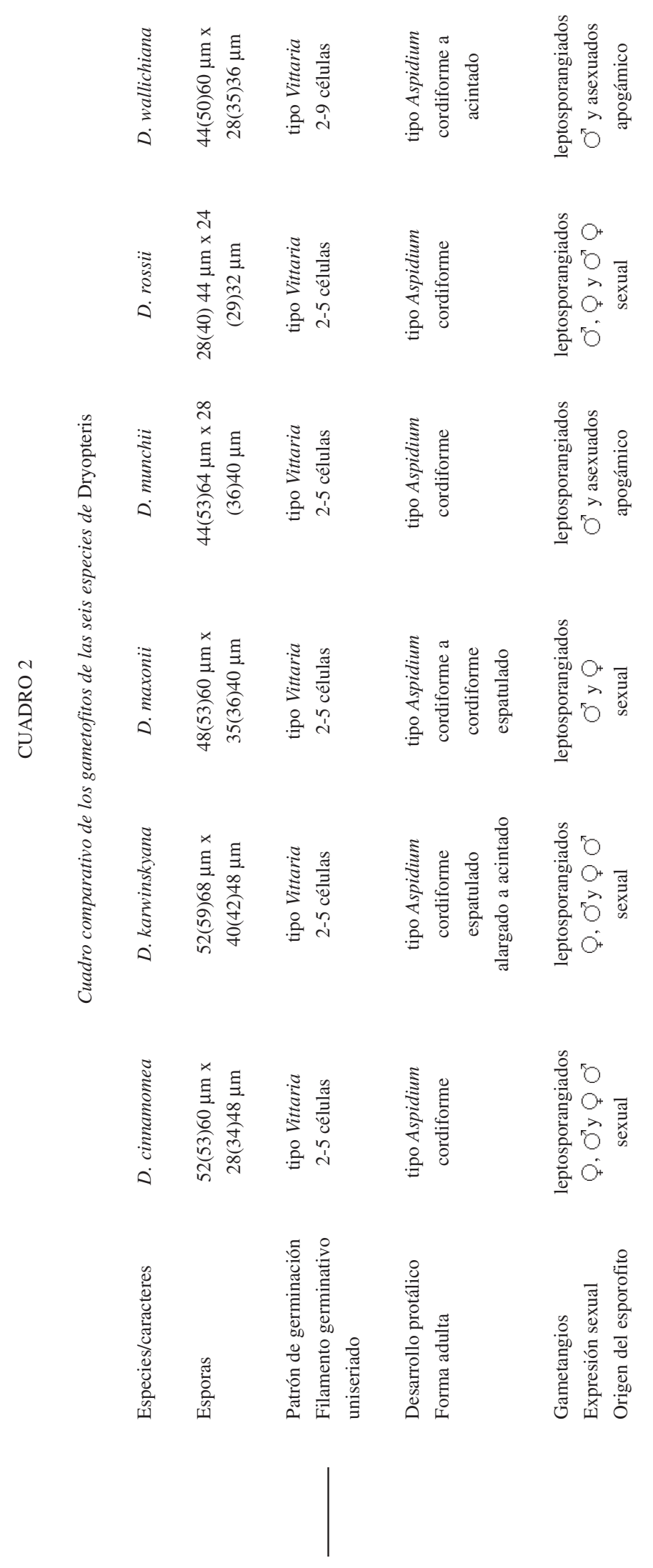


anteridios sobre la lámina que liberaban anterozoides numerosos y activos.

La apogamia es un fenómeno frecuente en muchos helechos, es una desviación del ciclo vital, en el cual hay formación de un esporofito a partir de células vegetativas del gametofito, sin la unión de gametos (Bold et al. 1987).

Sin lugar a dudas el género Dryopteris, presenta distintas estrategias para la formación de esporofitos viables, ya sea por su expresión sexual, por apogamia o bien por la formación de anteridiógenos (Voeller 1964), son vías que seguramente lo seguirán favoreciendo a lo largo de su evolución. Particularmente para $D$. munchii que es una especie de distribución restringida (endémico), la capacidad de formar esporofitos por medios apogámicos es una garantía de sobrevivencia cuando no hay las condiciones para propagarse sexualmente.

\section{AGRADECIMIENTOS}

Se reconoce el apoyo financiero del CONACyT (Clave: 3903-N94401) y a Jorge Lodigiani por el procesamiento del material fotográfico.

\section{RESUMEN}

Se describe y se compara la morfogénesis de la fase sexual de seis especies de Dryopteris. Las esporas son monoletes, elipsoidales con perina de color pardo a pardo obscuro, su superficie es rugosa de contornos tuberculados y la perina en forma de pliegues. El patrón de germinación en todas las especies es tipo Vittaria y el desarrollo protálico tipo Aspidium. Los gametangios son del tipo común de los helechos leptosporangiados del tipo avanzado, los cuellos de los arquegonios tienen cuatro hileras de células con 4 a 5 células cada una, se forman entre los 53-218 días. Los anteridios de las seis especies se formaron entre los 46-234 días después de sembradas las esporas y tienen 3 células que rodean a la célula androgénica. Los esporofitos se formaron entre los 60-262 días después de sembradas las esporas, como producto de la fecundación en $D$. cinnamomea, D. karwinskyana, D. maxonii y, D. rossii y son de origen apogámico en $D$. munchii y D. wallichiana.

\section{REFERENCIAS}

Atkinson, L.R. 1973. The gametophyte and family relationships. p. 73-90. In A.C. Jermy, J.A. Crabbe \& B.A. Thomas (eds.). The phylogeny and classification of the ferns. Academic, Nueva York.

Atkinson, L.R. \& A.G. Stokey. 1964. Comparative morphology of the gametophyte of homosporous ferns. Phytomorphology 14: 51-70.

Bold, H. C., C. J. Alexopoulos \& T. Delevoryas. 1987. Morfología de las plantas y los hongos. Omega, Barcelona. p. 434.

Cousens, M.I. 1975. Gametophyte sex expression in some species of Dryopteris. Amer. Fern J. 65: 39-42.

Cousens, M.I. \& H.T. Horner. Jr. 1970. Gametophyte ontogeny and sex expression in Dryopteris ludoviciana. Amer. Fern J. 60: 13-17.

Chandra, P. \& B. K. Nayar. 1970. Morphology of some polystichoid ferns. I. The gametophytes of Arachniodes, Cyrtomium and Polystichum. J. Linn. Soc. Bot. 63: 265-276.

Duncan, R. E. 1943. Origin and development of embryos in certain apogamous forms of Dryopteris. Bot. Gaz. (Crawfordsville) 105: 202-211.

Kanamori, K. 1967. Origin and early development of apogamous embryos in the protallia of Dryopteris chinensis. J. Jap. Bot. 42:111-118.

Kaur, S. 1977. Morphology of the prothallus and juvenile sporophytes of some species of Dryopteris. Proc. Indian Acad.Sci. 85b: 48-50.

Klekowski, E.J. Jr. 1969. Reproductive biology of the Pteridophyta. III. A study of the Blechnaceae. Bot. J. Linn. Soc. 62: 361-377.

Loyal, D.S. 1959. Some observations on the cytology and apogamy of Himalayan Dryopteris paleacea (Don.) Hand-Mazz. J. Indian Bot. Soc. 39: 608-613.

Manton, I. \& S. Walker. 1954. Induced apogamy in Dryopteris dilatata (Hoffm.) A. Gray and D. filix-mas (L.) Schott emend. and its significance for the interpretation of the two species. Ann. Bot. (London) 18: 377-383.

Mendoza, A., B. Pérez-García \& R. Riba. 1999. Morfología y anatomía del gametofito de Didymochlaena truncatula (Dryopteridaceae) Rev. Biol. Trop. 47: 83-89. 
Momose, S. 1937. Studies on the gametophyte of ferns. I. On the prothallial development and prothallium of Dryopteris varia O. Kuntze. J. Jap. Bot. 12: 113-120.

Moran, R.C. 1986. The neotropical fern genus Olfersia. Amer. Fern J. 76: 161-178.

Moran, R.C. 1987a. Monography of the neotropical fern genus Polybotrya (Dryopteridaceae). Bull. Illinois Nat. Hist. Surv. 34: 1-138.

Moran, R.C. 1987b. Sterile-fertile leaf dimorphy and the evolution of soral type in Polybotrya (Dryopteridaceae). Syst. Bot. 12: 617-628.

Moran, R.C. 1991. Monograph of the neotropical fern genus Stigmatopteris (Dryopteridaceae). Ann. Missouri Bot. Gard. 78: 857-914.

Moran, R.C. 1995. Dryopteridaceae, p. 210-226. In R.C. Moran. y R. Riba (eds.). Flora Mesoamericana, vol. 1, Psilotaceae a Salviniaceae. Instituto de Biología, Jardín Botánico de Missouri y Museo de Historia Natural de Londres.

Nayar, B.K. \& S. Kaur. 1969. Types of prothallial development in homosporous ferns. Phytomorphology 19: 179-188.
Nayar, B.K. \& S. Kaur. 1971. Gametophytes of homosporous ferns. Bot. Rev. 37: 295-396.

Riba, R. \& B. Pérez-García. 1999. Dryopteridaceae. Flora de México, Vol.6. Consejo Nacional de la Flora de México, A. C. (6: 1-48)

Stokey, A.G. \& L.R. Atkinson. 1954. The gametophyte of Didymochlaena sinuata Desv. Phytomorphology 4: 310-315.

Tryon, A.F. \& B. Lugardon. 1991. Spores of the Pteridophyta: surface, wall structure, and diversity based on electron microscope studies: i-x. Springer-Verlag, Nueva York. pp. 440 - 441.

Voeller, B. 1964. Antheridogens in ferns In Regulateurs Naturels de la Croissance Végétale. Colloq. Internat. Centre Nat. Rech. Sci., Paris 123: 665-684.

Yatskievych, G. 1990. Systematic of the fern genus Cyrtomium in the New World. Ph. D. thesis: i-xii, 1-239. Indiana University; Bloomington, Indiana.

Yatskievych, G. 1992. Innovations in the fern genus Phanerophlebia. Novon 2: 445-446. 